JOSETA: Journal of Socio Economic on Tropical Agriculture

Volume 1 Nomor 1: 52-60 April (2019)

JOSETA: Journal of Socio Economic on Tropical Agriculture http://joseta.faperta.unand.ac.id

ISSN : $2686-0953$ (online)

\title{
ANALISIS STRATEGI PENGEMBANGAN UKM (STUDI KASUS : USAHA RESTORAN BAKMI JA DI KOTA PADANG)
}

Putri Kurnia $^{1 *}$,Lora Triana ${ }^{2}$, Rina Sari ${ }^{3} 11 \mathrm{pt}$

${ }^{1}$ Universitas Andalas, Limau Manis,

${ }^{2}$ Universitas Andalas, Limau Manis,Padang 25114

${ }^{3}$ Universitas Andalas, Limau Manis,Padang 25114

lora.triana@gmail.com

Received: $20^{\text {th }}$ Februari, 2019; $1^{\text {st }}$ Revision: $12^{\text {th }}$ Maret, 2019; Accepted: $18^{\text {th }}$ April, 2019

\begin{abstract}
Abstrak
Penelitian ini dilakukan pada usaha kecil menengah (UKM) di Kota Padang dengan studi kasus pada Restoran Bakmi JA di Kota Padang. Tujuan penelitian untuk menggambarkan profil usaha Restoran Bakmi JA, menganalisis lingkungan strategis internal dan eksternal serta merumuskan strategi pengembangan usaha Restoran Bakmi JA. Jenis penelitian ini merupakan penelitian kualitatif dengan metode studi kasus. Analisis data menggunakan matriks SWOT dan matriks QSPM. Tujuan dari pengembangan yang ingin dicapai adalah untuk meningkatkan pendapatan dan bertahan pada tingkat persaingan yang tinggi. Untuk meningkatkan pendapatan dan bertahan pada persaingan yang tinggi, maka dirumuskan beberapa strategi yang terdiri dari: (1) meningkatkan dan menjaga kualitas produk, (2) meningkatkan kualitas pelayanan kepada konsumen, (3) melakukan promosi yang lebih intensif melalui media internet dan elektronik, (4) melakukan riset untuk mengukur tingkat kepuasan konsumen. Berdasarkan hasil penelitian, sebaiknya Restoran Bakmi JA fokus terhadap peningkatan kualitas produk serta peningkatan pelayanan, sehingga bisa menghadapi persaingan di industrikuliner Kota Padang.
\end{abstract}

Kata kunci :strategi pengembangan, industri kecil menengah, restoran, SWOT, QSPM

\section{Abstract}

This research was conducted on small-middle business in Padang City, which case study on Bakmi JA Restorant. The purpose of this research are to identify profile of Bakmi JA restorant, to analyze internal and external environmental and formulate development strategies of Bakmi JA restorant. This reseach is a qualitative research using case study method. Data analysis using SWOT matrix dan QSPM matrix. The goal of the development to be achieved are to increase the income and facing competitors. So that, strategies that applied to Bakmi JA are 1) improving and maintainingproduct quality, 2)improving service quality to consumer, 3) intensive promotion through internet media and electronic and 4) Doing customer satisfaction research. Based of this research, Restoran Bakmi $J A$ should be focus on improving product and services quality to face the competitors in culinary industry.

Keywords :agribussiness, agriculture,coffee

\section{PENDAHULUAN}

Indonesia merupakan salah satu negara agraris terbesar di dunia. Sebagian besar penduduk Indonesia hidup dari sektor agribisnis. Agribisnis merupakan suatu sistem yang integratif terdiri dari beberapa subsistem yaitu subsistem pengadaan sarana produksi pertanian, subsistem produksi pertanian, subsistem pengolahan dan industri hasil pertanian serta pemasaran, dan subsistem kelembagaan penunjang kegiatan pertanian (Krisnamurthi, 2001: 6). 
Subsistem pengolahan dan pemasaran tergolong kepada subsistem hilir (down-stream agribusiness), Kegiatan pengolahan komoditas primer adalah kegiatan yang memproduksi produk olahan baik produk setengah jadi maupun produk jadi yang siap dikonsumsi oleh konsumen dengan menggunakan bahan baku komoditas primer. Sedangkan kegiatan pemasaran adalah kegiatan memasarkan dan menghadirkan produk berupa komoditas primer maupun produk olahan kepada konsumen dalam bentuk, tempat, waktu yang tepat.Salah satu industri

Usaha Kecil Menengah (UKM) memiliki peran yang sangat besar terhadap sub system hilir di Indonesia. Menurut Hapsari (2014), Usaha Mikro, Kecil dan Menengah (UMKM) merupakan salah satu bagian penting dari perekonomian suatu bangsa dan daerah tak terkecuali di Indonesia. UMKM merupakan salah satu motor penggerak perekonomian di Indonesia. Sejak krisis moneter di tahun 19971998 hampir 80\% usaha yang dikategorikan besar mengalami kebangkrutan, malah UMKM dapat bertahan dalam krisis sengan segala keterbatasan dan kemampuan yang dimilikinya.

Salah satu Usaha Kecil Menengah (UKM) yang ada di Kota Padang yaitu Bakmi JA yang berada di Jalan S. Parman no. 82A, Kecamatan Padang Utara. Bakmi JA menawarkan sajian bakmi dengan inovasi seperti bakmi bayam, bakmi wortel, bakmi naga, dan bakmi ubi. Bakmi JA adalah satu-satunya restoran bakmi yang menawarkan inovasi bakmi sehat. Permasalahan yang dihadapi restoran Bakmi JA yaitu restoran ini mengalami penurunan penjualan selama bulan Juli, Agustus, September, dan Oktober tahun 2017. Penurunan penjualan ini diakibatkan tingkat persaingan yang tinggi di bidang industri kuliner di Kota Padang. Pesaing Bakmi JA yang juga bergerak di bidang restoran bakmi adalah Bakmi DKI yang sudah memiliki dua cabang di Kota Padang. Untuk menghadapi persaingan tersebut, maka dibutuhkan strategi pengembangan yang tepat agar restoran Bakmi JA dapat mengembangkan usahanya.

Berdasarkan uraian di atas, maka tujuan penelitian ini adalah : (1) Menggambarkan profil usaha Restoran Bakmi JA (2) Menganalis lingkungan strategis internal dan eksternal dalam pengembangan usaha Restoran Bakmi JA di Kota Padang

dan (3) Merumuskan strategi pengembangan usaha yang dapat diterapkan oleh restoran Bakmi JA.

\section{METODE PENELITIAN}

Penelitian ini dilaksanakan di Kota Padang, yaitu di Restoran Bakmi JA yang beralamat di Jalan S. Parman No. 82A, Padang. Pemilihan tempat dilakukan dengan pertimbangan restoran ini merupakan satu-satunya restoran bakmi di Kota Padang yang menawarkan inovasi menu berupa bakmi sehat dan Restoran Bakmi JA merupakan satu-satunya restoran bakmi di Kota Padang yang mengalami penurunan penjualan secara berturut-turut selama 4 bulan yakni pada bulan Juli, Agustus, September, dan Oktober pada tahun 2017. Penelitian ini dilaksanakan selama satu bulan, yakni pada bulan April - Juni 2018.

Jenis penelitian ini merupakan penelitian kualitatif dengan metode studi kasus (case study). Penelitian kualitatif merupakan prosedur penelitian yang menghasilkan data deskriptif yang dapat berupa kata-kata tertulis atau lisan yang didapatkan dari berbagai sumber yang terkait dengan penelitian.studi kasus. Menurut Bungin (2005:65), metode studi kasus lebih banyak berupaya untuk menjawab pertanyaan-pertanyaan "how" (bagaimana) dan "why" (mengapa), serta pada tingkatan tertentu juga menjawab pertanyaan "what" (apa/apakah) dalam kegiatan penelitian.

Hal yang diteliti dalam penelitian ini adalah tentang gambaran faktor-faktor internal dan eksternal pada Restoran Bakmi JA sehingga dapat dirumuskan alternatif strategi strategi untuk mengembangkan usaha Restoran Bakmi JA di Kota Padang. Hal ini dilakukan agar strategi yang dirumuskan tersebut dapat diaplikasikan sehingga bisa meningkatkan kualitas, kuantitas pada produk, dan meningkatkan penjualan Restoran Bakmi JA

Adapun responden yang digunakan dalam penelitian ini berasal dari pihak internal dan eksternal dari Restoran Bakmi JA. Responden yang dijadikan sebagai narasumber adalah : (1)Pihak internal usaha Restoran Bakmi JA, terdiri dari pemilik usaha dan tenaga kerja. Pihak eksternal usaha Restoran Bakmi JA, terdiri dari konsumen Restoran Bakmi JA dan pesaing utama.

Analisis yang digunakan dalam penelitian ini adalah analisa deskriptif kualitatif dan deskriptif kuantitatif.Analisis kualitatif adalah menggambarkan kondisi dan menjelaskan fakta-fakta yang terjadi 
pada usaha Restoran Bakmi JA di Kota Padang dan perumusan strategi yang tepat pada usaha Restoran Bakmi JA.Sedangkan analisis kuantitatif dilakukan pada perhitungan Internal Factor Evaluation (IFE), External Factor Evaluation (EFE), dan Quantitive Strategies Planning Matrix (QSPM).Untuk menjawab tujuan pertama menggunakan deskriptif kualitatif yang digunakan untuk mengidentifikasi faktor lingkungan internal dan faktor eksternal usaha Restoran Bakmi JA.

Untuk tujuan kedua yaitu mengidentifikasi faktor internal dan eksternal yang mempengaruhi Restoran Bakmi JA dalam menjalankan usahanya digunakan analisis deskriptif kualitatif sehingga mampu menggambarkan fakta-fakta yang bersangkutan dengan usaha Restoran Bakmi JA yang ditinjau dari gambaran lingkungan strategis internal dan eksternal usaha Restoran Bakmi JA berupa gambaran lingkungan internal yang terdiri dari aspek manajemen, aspek keuangan, aspek pemasaran, aspek produksi/operasi, dan aspek penelitian serta pengembangan. Selanjutnya dari gambaran lingkungan eksternal yang terdiri dari aspek sosial, budaya, aspek lingkungan politik, pemerintahan dan hukum, aspek ekonomi, aspek teknologi, dan aspek pesaing.

Kemudian untuk menjawab tujuan ketiga penelitian yaitu merumuskan strategi pengembangan usaha yang dapat diterapkan oleh Restoran Bakmi JA adalah dengan menggunakan analisa deskriptif kuantitatif. Perumusan strategi usaha Restoran Bakmi JA dilakukan melalui tiga tahap yaitu 1) Tahap masukan (input stage) dengan menggunakan matriks IFE dan EFE, 2) Tahap pencocokkan (matching stage) dengan menggunakan matriks SWOT, 3) Tahap keputusan (decision stage) dengan menggunakan matriks QSPM

\section{HASIL DAN PEMBAHASAN}

\section{Profil Restoran Bakmi JA}

Restoran Bakmi JA terletak di jalan S Parman no. 82 A. Pemilik usaha ini bernama Bapak Jelvi. Nama Bakmi JA memiliki kepanjangan Jalan Allah. Bakmi JA memberikan potongan harga sebesar 10\% setiap hari Jumat, yang dinamakan program Jumat Berkah. Berdasarkan wawancara dengan pemilik restoran, visi Bakmi JA adalah sebagai berikut:"Menjadi restoran Bakmi nomor satu di Kota Padang" dengan merumuskan misi sebagai berikut:
a. Menjalin dan menjaga hubungan baik antar seluruh anggota usaha
b. Mempertahankan kualitas rasa produk dengan harga yang bersaing
c. Meningkatkan kulaitas produk dengan bahan yang berkualitas dan penyajian yang baik

\section{2. Identifikasi Faktor-Faktor Internal dan Eksternal} a. Lingkungan Internal

Berdasarkan indentifikasi faktor-faktor yang terdapat pada aspek-aspek dalam usaha Restoran Bakmi JA, maka dapat dikelompokkan ke dalam lingkungan internal berupa kekuatan dan kelemahan dapat dilihat pada tabel 1berikut :

Tabel 1. Ringkasan Faktor Strategis Lingkungan Internal Restoran Bakmi JA

\begin{tabular}{|c|c|c|c|}
\hline No & Lingkungan Internal & Kekuatan & Kelemahan \\
\hline 1 & Aspek Manajemen & $\begin{array}{l}\text { 1. Pengawasan yang dilakukan } \\
\text { setiap hari oleh manager } \\
\text { perusahaan }\end{array}$ & $\begin{array}{ll}\text { 1. } & \text { Tidak adanya standar } \\
\text { operasional prosedur (SOP) } \\
\text { pada perusahaan } \\
\text { 2. Perencanaan belum } \\
\text { dilakukan secara tertulis } \\
\text { dan tidak diketahui oleh } \\
\text { seluruh elemen perusahaan }\end{array}$ \\
\hline 2 & Aspek Keuangan & 2. $\begin{array}{l}\text { Menggunakan modal milik } \\
\text { sendiri }\end{array}$ & \\
\hline 3 & Aspek Pemasaran & $\begin{array}{l}\text { 3. Lokasi yang strategis } \\
\text { 4. Papan nama yang menarik } \\
\text { 5. Bermitra dengan aplikasi }\end{array}$ & $\begin{array}{l}\text { 3. Lahan parkir yang sempit } \\
\text { 4. Promosi belum dilakukan } \\
\text { secara kontinyu }\end{array}$ \\
\hline
\end{tabular}




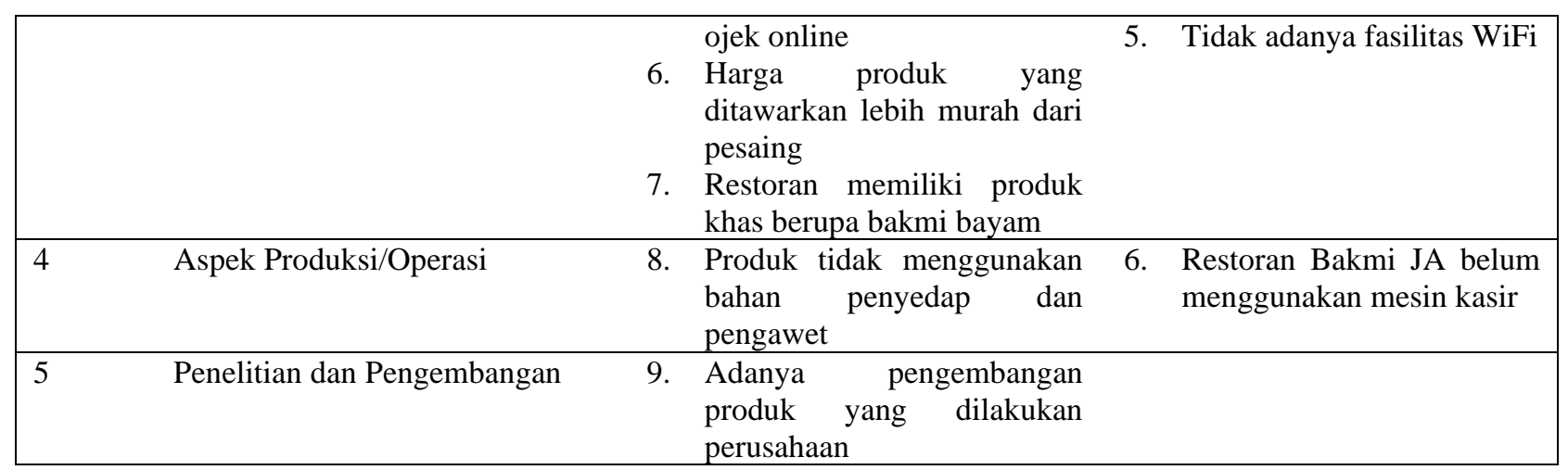

\section{b. Lingkungan Eksternal}

Berdasarkan identifikasi factor-faktor yang berpengaruh, maka dapat dikelompokkan ke dalam factorfaktor lingkungan eksternal berupa peluang dan ancaman. Ringkasan faktor strategi lingkungan aksternal dari Restoran Bakmi JA adalah :

Tabel 2. Ringkasan Faktor Strategis Lingkungan Eksternal Restoran Bakmi JA

\begin{tabular}{|c|c|c|c|}
\hline No & Lingkungan Internal & Kekuatan & Kelemahan \\
\hline 1 & Aspek Manajemen & 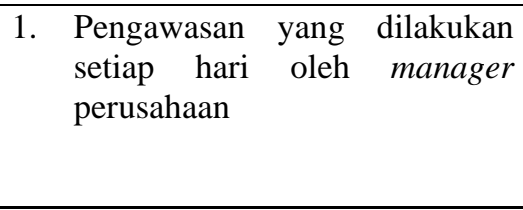 & $\begin{array}{l}\text { 1. Tidak adanya standar operasional } \\
\text { prosedur (SOP) pada perusahaan } \\
\text { 2. Perencanaan belum dilakukan secara } \\
\text { tertulis dan tidak diketahui oleh } \\
\text { seluruh elemen perusahaan } \\
\end{array}$ \\
\hline 2 & Aspek Keuangan & 3. $\begin{array}{l}\text { Menggunakan modal milik } \\
\text { sendiri }\end{array}$ & \\
\hline 3 & Aspek Pemasaran & $\begin{array}{l}\text { 4. Lokasi yang strategis } \\
\text { 5. Papan nama yang menarik } \\
\text { 6. Bermitra dengan aplikasi ojek } \\
\text { online } \\
\text { 7. Harga produk yang ditawarkan } \\
\text { lebih murah dari pesaing } \\
\text { 8. Restoran memiliki produk } \\
\text { khas berupa bakmi bayam }\end{array}$ & $\begin{array}{l}\text { 2. Lahan parkir yang sempit } \\
\text { 3. Promosi belum dilakukan secara } \\
\text { kontinyu } \\
\text { 4. Tidak adanya fasilitas WiFi }\end{array}$ \\
\hline 4 & Aspek Produksi/Operasi & $\begin{array}{l}\text { 9. Produk tidak menggunakan } \\
\text { bahan penyedap dan pengawet }\end{array}$ & $\begin{array}{llr}\text { 5. } & \begin{array}{l}\text { Restoran } \\
\text { menggunakan mesin kasir }\end{array} & \text { belum } \\
\end{array}$ \\
\hline 5 & $\begin{array}{l}\text { Penelitian dan } \\
\text { Pengembangan }\end{array}$ & $\begin{array}{l}\text { 9. Adanya pengembangan produk } \\
\text { yang dilakukan perusahaan }\end{array}$ & \\
\hline
\end{tabular}

\section{Analisis Matriks IFE dan EFE}

Matriks IFE merupakan hasil identifikasi faktor-faktor internal pengembangan Restoran Bakmi JA yang berupa kekuatan dan kelemahan dalam usaha Restoran Bakmi JA.Sedangkan matriks EFE merupakan hasil identifikasi faktor-faktor eksternal yang mempengaruhi pengembangan usaha Restoran Bakmi JA yang berupa peluang dan ancaman dalam pengembangan usaha Restoran Bakmi JA.

Proses pembobotan pada matriks IFE dan EFE dilakukan oleh pakar yang telah dientukan dan pemilik Restoran Bakmi JA, faktor strategis internal dan eksternal yang diberikan bobot dan peringkat diseleksi oleh pakar dan pemilik hanya dipilih kekuatan mayor dan kelemahan mayor yang akan diberikan bobot dan peringkat. Adapun hasil pembobotan dan peratingan pada matriks IFE dan EFE oleh pakar dan pemilik dapat dilihat pada Tabel 3 dan 4.

Berdasarkan hasil rata-rata tertimbang pada matriks IFE yaitu sebesar 2.73, menunjukkan posisi internal Bakmi JA yang kuat. Menurut David (2009), total nilai rata-rata tertimbang di 
bawah 2.5 merupakan ciri organisasi yang lemah secara internal, sedangkan di atas 2.5 menunjukkan posisi internal yang kuat.

Dari hasil nilai rata-rata tertimbang pada matriks EFE di bawah, yaitu sebesar 2.66, maka sudah di atas rata-rata nilai tertimbang, yaitu 2.5. Artinya restoran Bakmi JA sudah memberi respon yang bagus terhadap peluang dan ancaman yang ada dalam industrinya. Menurut David (2009), rata-rata nilai yang dibobot adalah 2.5, jumalh nilai yang dibobot sama sengan 4.0 menunjukkan bahwa suatu organisasi memberi respon yang sangat bagus terhadap peluang dan ancaman yang ada dalam industrinya. Jumlah nilai yang dibobot sama dengan 1.0, menunjukkan bahwa strategi perusahaan tidak memanfaatkan peluang atau menghindari ancaman eksternal.

Tabel 3. Analisis Matriks IFE (Internal Factor Evaluation) Restoran Bakmi JA

\begin{tabular}{|c|c|c|c|c|}
\hline No & Faktor Strategis Internal & $\begin{array}{c}\text { Nilai } \\
\text { Bobot }\end{array}$ & Nilai Peringkat & $\begin{array}{c}\text { Rata-Rata } \\
\text { Tertimbang }\end{array}$ \\
\hline & \multicolumn{4}{|l|}{ Kekuatan } \\
\hline 1 & $\begin{array}{l}\text { Pengawasan yang dilakukan setiap hari oleh } \\
\text { manager perusahaan }\end{array}$ & 0.06 & 3 & 0.19 \\
\hline 2 & Menggunakan modal milik sendiri & 0.05 & 4 & 0.21 \\
\hline 3 & Lokasi yang strategis & 0.08 & 3 & 0.23 \\
\hline 4 & Papan nama yang menarik & 0.06 & 3 & 0.19 \\
\hline 5 & Bermitra dengan aplikasi ojek online & 0.07 & 3 & 0.21 \\
\hline 6 & $\begin{array}{l}\text { Harga produk yang ditawarkan lebih murah dari } \\
\text { pesaing }\end{array}$ & 0.06 & 3 & 0.19 \\
\hline 7 & $\begin{array}{l}\text { Restoran memiliki produk khas berupa bakmi } \\
\text { bayam }\end{array}$ & 0.06 & 4 & 0.26 \\
\hline 8 & $\begin{array}{l}\text { Produk tidak menggunakan bahan penyedap dan } \\
\text { pengawet }\end{array}$ & 0.08 & 4 & 0.31 \\
\hline \multirow[t]{2}{*}{9} & $\begin{array}{l}\text { Adanya pengembangan produk yang dilakukan } \\
\text { perusahaan }\end{array}$ & 0.07 & 4 & 0.28 \\
\hline & Jumlah & 0.60 & 31 & 2.07 \\
\hline & Kelemahan & & & \\
\hline 1 & $\begin{array}{l}\text { Tidak adanya standar operasional prosedur (SOP) } \\
\text { pada perusahaan }\end{array}$ & 0.07 & 1 & 0.07 \\
\hline 2 & $\begin{array}{l}\text { Perencanaan belum dilakukan secara tertulis dan } \\
\text { tidak diketahui oleh seluruh elemen perusahaan }\end{array}$ & 0.07 & 2 & 0.14 \\
\hline 3 & Lahan parkir yang sempit & 0.06 & 2 & 0.13 \\
\hline 4 & Promosi belum dilakukan secara kontinyu & 0.06 & 2 & 0.12 \\
\hline 5 & $\begin{array}{l}\text { Restoran Bakmi JA belum menggunakan mesin } \\
\text { kasir }\end{array}$ & 0.07 & 2 & 0.14 \\
\hline \multirow[t]{3}{*}{6} & Tidak adanya fasilitas WiFi & 0.06 & 1 & 0.06 \\
\hline & Jumlah & 0.40 & 10 & 0.66 \\
\hline & Total & 1.00 & 41 & 2.73 \\
\hline
\end{tabular}


Tabel 4. Analisis Matriks EFE (External Factor Evaluation) Restoran Bakmi JA

\begin{tabular}{|c|c|c|c|c|}
\hline No & Faktor Strategis Internal & $\begin{array}{l}\text { Nilai } \\
\text { Bobot }\end{array}$ & Nilai Peringkat & $\begin{array}{l}\text { Nilai Rata-Rata } \\
\text { Tertimbang }\end{array}$ \\
\hline & Peluang & & & \\
\hline 1 & $\begin{array}{l}\text { Tingkat inflasi yang rendah dan cenderung } \\
\text { stabil }\end{array}$ & 0.12 & 2 & 0.24 \\
\hline 2 & $\begin{array}{l}\text { Peralihan gaya hidup masyarakat yang } \\
\text { cenderung mengkonsumsi makanan siap saji }\end{array}$ & 0.11 & 4 & 0.45 \\
\hline 3 & $\begin{array}{l}\text { Pertumbuhan jumlah penduduk Kota Padang } \\
\text { membuka peluang tersedianya pasar potensial }\end{array}$ & 0.10 & 3 & 0.31 \\
\hline \multirow[t]{2}{*}{4} & Kemajuan teknologi & 0.12 & 3 & 0.37 \\
\hline & $\begin{array}{l}\text { Jumlah } \\
\text { Ancaman }\end{array}$ & 0.46 & 12 & 1.37 \\
\hline 1 & $\begin{array}{l}\text { Respon konsumen terhadap kenaikan harga } \\
\text { produk }\end{array}$ & 0.10 & 3 & 0.31 \\
\hline 2 & $\begin{array}{l}\text { Budaya masyarakat yang cenderung lebih } \\
\text { memilih nasi sebagai makanan utama }\end{array}$ & 0.11 & 3 & 0.34 \\
\hline 3 & $\begin{array}{l}\text { Kenaikan harga bahan baku yang dipengaruhi } \\
\text { oleh kenaikan BBM }\end{array}$ & 0.11 & 2 & 0.22 \\
\hline 4 & Banyaknya produk substitusi & 0.09 & 2 & 0.18 \\
\hline \multirow[t]{3}{*}{5} & Kecilnya hambatan untuk masuk industry & 0.12 & 2 & 0.24 \\
\hline & Jumlah & 0.54 & 12 & 1.30 \\
\hline & Total & 1.00 & 24 & 2.66 \\
\hline
\end{tabular}

\section{Tahap Pencocokan : Matriks SWOT (Strengths-Weakness-Opportunities-Threats)}

Matriks SWOT merupakan suatu alat analisis yang digunakan untuk menyusun faktor-faktor lingkungan internal dan eksternal dari Restoran Bakmi JA. Tidak semua strategi yang dikembangkan dalam matriks SWOT akan dipilih untuk diimplementasikan. Empat strategi yang disarankan yaitu strategi SO (strength-opportunities/kekuatan-peluang).strategi WO (weakness-opportunities/kelemahanpeluang), strategi ST (strength-threats/kekuatan-ancaman), dan strategi WT (weaknessthreats/kelemahan-ancaman). Peneliti memilih menggunakan matriks SWOT karena sesuai dengan indikator pada faktor-faktor internal dan eksternal dapat dilihat pada Tabel 5.

Tabel 5. Matriks SWOT Restoran Bakmi JA

\begin{tabular}{|c|c|c|}
\hline Internal & $\begin{array}{l}\text { Strength }(S) \\
\text { 1. Pengawasan yang dilakukan setiap } \\
\text { hari oleh manager perusahaan } \\
\text { 2. Menggunakan modal milik sendiri } \\
\text { 3. Lokasi yang strategis } \\
\text { 4. Papan nama yang menarik } \\
\text { 5. Bermitra dengan aplikasi ojek online } \\
\text { 6. Harga produk yang ditawarkan lebih } \\
\text { 7. } \text { murah dari pesaing } \\
\text { berupa bakmi bayam }\end{array}$ & $\begin{array}{l}\text { Weakness }(W) \\
\text { 1. } \\
\text { Tidak adanya standar } \\
\text { operasional prosedur (SOP) } \\
\text { pada perusahaan } \\
\text { 2. } \text { Perencanaan belum dilakukan } \\
\text { secara tertulis dan tidak } \\
\text { diketahui oleh seluruh elemen } \\
\text { perusahaan } \\
\text { 3. Lahan parkir yang sempit } \\
\text { 4. } \quad \text { Promosi belum dilakukan } \\
\text { secara kontinyu }\end{array}$ \\
\hline
\end{tabular}




\begin{tabular}{|c|c|c|}
\hline Eksternal & $\begin{array}{l}\text { 8. Produk tidak menggunakan bahan } \\
\text { penyedap dan pengawet } \\
\text { 9. Adanya pengembangan produk yang } \\
\text { dilakukan perusahaan }\end{array}$ & $\begin{array}{ll}\text { 5. } & \text { Restoran Bakmi JA belum } \\
\text { menggunakan mesin kasir } \\
\text { 6. } & \text { Tidak adanya fasilitas WiFi }\end{array}$ \\
\hline \begin{tabular}{ll}
\multicolumn{2}{c}{ Opportunities $(O)$} \\
1. Tingkat inflasi yang rendah \\
dan cenderung stabil \\
2. Peralihan gaya hidup \\
masyarakat yang cenderung \\
mengkonsumsi makanan \\
siap saji \\
3. Pertumbuhan jumlah \\
penduduk Kota Padang \\
membuka peluang \\
tersedianya pasar potensial \\
4. Kemajuan teknologi
\end{tabular} & $\begin{array}{l}\text { Strategi SO } \\
\text { 1. } \begin{array}{l}\text { Meningkatkan dan menjaga kualitas } \\
\text { produk (S6, S7, S8, S9 dan O2,O3) }\end{array}\end{array}$ & \begin{tabular}{lr}
\multicolumn{2}{c}{ Strategi WO } \\
1. & $\begin{array}{l}\text { Meningkatkan } \\
\text { pelayanan kepada }\end{array}$ \\
konsumen \\
(W1,W3,W5,W6 \\
O2,03,04)
\end{tabular} \\
\hline $\begin{array}{l}\text { Threats }(T) \\
\text { 1. Respon konsumen terhadap } \\
\text { kenaikan harga produk } \\
\text { 2. Budaya masyarakat yang } \\
\text { cenderung lebih memilih } \\
\text { nasi sebagai makanan utama } \\
\text { 3. Kenaikan harga bahan baku } \\
\text { yang dipengaruhi oleh } \\
\text { kenaikan BBM } \\
\text { 4. Banyaknya produk substitusi } \\
\text { 5. Kecilnya hambatan untuk } \\
\text { masuk industri }\end{array}$ & $\begin{array}{l}\text { Strategi ST } \\
\text { 1. Meningkatkan promosi yang lebih } \\
\text { intensif melalui media internet dan } \\
\text { elektronik (S3,S4,S5,S6,S7,S8,S9 } \\
\text { dan T2,T4,T5) }\end{array}$ & $\begin{array}{l}\text { Strategi WT } \\
\text { 1. Melakukan riset untuk } \\
\text { mengukur tingkat kepuasan } \\
\text { konsumen (WI,W3,W4,W6 } \\
\text { dan T1,T2,T3,T5) }\end{array}$ \\
\hline
\end{tabular}




\section{Tahap Keputusan: Analisis Matriks QSPM (Quantitative Strategic Planning Matrix)}

Setelah diperoleh beberapa alternatif strategi melalui tahap pencocokan yaitu dengan matiks SWOT, maka tahap akhir dari analisis strategi adalah pemilihan strategi yang terbaik.Adapun alat analisis yang di gunakan pada tahap pengambilan keputusan ini adalah Quantitative Srategic Planning Matrix (QSPM). Teknik ini menggunakan input dari analisis tahap pemanduan untuk menentukan secara objektif diantara alternatif strategi yang dihasilkan dari matriks SWOT pada tahap pencocokan.

Nilai AS (Attractive Score) didapatkan dari nilai yang telah diberikan oleh pemilik Restoran Bakmi JA, Bapak Jelvi Amri.Nilai TAS (Total Attractive Score) didapatkan dari hasil perkalian antara nilai AS dengan bobot dari setiap faktor kunci strategis. Kemudian dilanjutkan STAS (Sum Total Attractive Score) dengan cara menjumlahkan seluruh nilai TAS dari faktor internal dan eksternal. Penjabaran dari strategistrategi tersebut berdasarkan hasil QSPM sebagai berikut :

a. Meningkatkan dan menjaga kualitas produk (TAS $=6,78)$

b. Meningkatkan kualitas pelayanan kepada konsumen (TAS $=5,28)$

c. Meningkatkan promosi dan pemasaran yang lebih intensif melalui media internet dan elektronik (TAS $=6,10)$

d. Melakukan riset untuk mengukur tingkat keupasan konsumen (TAS $=6,20$ )

Berdasarkan hasil analisis matriks QSPM, bahwa strategi terbaik yang harus dilakukan saat ini adalah meningkatkan dan menjaga kualitas produk dengan nilai TAS sebesar 6,78. Kualitas produk merupakan aspek penting yang akan diperhatikan oleh konsumen sebelum mereka memutuskan untuk melakukan pembelian suatu produk. Apabila ingin menciptakan kepuasan pelanggan, maka produk yang ditawarkan perusahaan juga harus berkualitas.

Menurut Tjiptono (2007 : 68) tentang dimensi kualitas produk yang dapat dilakukan Restoran Bakmi JA untuk meningkatkan dan menjaga kualitas produknya, diantaranya :

1. Produk yang disajikan higienis (perfomance)

2. Menawarkan menu makanan yang lebih bervariasi (feature)

3. Menawarkan porsi yang lebih banyak dari restoran lain (feature)

4. Jika menu tidak sesuai dengan pesanan pelanggan, karyawan mau menggantinya (reliability)

5. Menyajikan makanan dengan cepat (servicability)

6. Restoran Bakmi JA memiliki kualitas rasa yang enak (aesthetics)

7. Kualitas makanan yang disajikan sesuai dengan uang yang dikeluarkan (perceived quality)

Dari ke delapan dimensi kualitas produk menurut Tjiptono, hanya enam dimensi yang dapat diterapkan pada strategi Restoran Bakmi JA, yakni dimensi perfomance (kinerja), feature (fitur), reliability (reliabilitas), serviceability, estetika (aesthetics), dan perceived quality (persepsi). Dua dimensi yang tidak dapat dapat diterapkan yaitu konformasi (conformance) dan durability (ketahanan) dua dimensi tersebut tidak dapat diterapkan karena produk yang ditawarkan berupa makanan sehingga tidak ada standar tertentu yang ditetapkan untuk produk makanan dan produk berupa makanan merupakan jenis produk yang cepat rusak.Dengan menerapkan strategi menjaga dan meningkakan kualitas produk makanan, diharapkan Restoran Bakmi JA dapat mempertahankan konsumen/pelanggan yang sudah ada dan menarik calon konsumen, sehingga tujuan pengembangan untuk meningkatkan pedapatan dan bertahan pada persaingan usaha yang cukup tinggi dapat tercapai.

\section{KESIMPULAN}

Pada analisis lingkungan internal, yang menjadi kekuatan utama restoran Bakmi JA adalah produk tidak menggunakan penyedap dan pengawet, sedangkan yang menjadi kelemahan utama adalah tidak adanya fasilitas wifi. Pada analisis lingkungan eksternal, yang menjadi peluang utama bagi Bakmi JA adalah peralihan gaya hidup masyarakat yang cenderung mengkonsumsi makanan siap saji, serta yang menjadi ancaman paling besar bagi Bakmi JA adalah budaya masyarakat yang memilih nasi sebagai makanan utama. Strategi pengembangan yang dipilih yaitu :1) Meningkatkan dan menjaga kualitas 
produk, 2) Meningkatkan kualitas pelayanan kepada konsumen, 3) Meningkatkan promosi dan pemasaran yang lebih intensif melalui media internet dan elektronik, dan 4)Melakukan riset untuk mengukur tingkat keupasan konsumen.

\section{UCAPAN TERIMA KASIH}

Terimakasih yang sebesar-besarnya penulis tujukan kepada Restoran Bakmi JA atas kesediaannya menjadi objek penelitian, kepada Pembimbing, Ibu Lora Triana dan Ibu Rina Sari yang sudah membantu membimbing penulis dalam menyelesaikan penelitian ini.

\section{Daftar Pustaka}

Bungin, Burhan. 2005. Metode Penelitian Kuantitatif Komunikasi Ekonomi dan Kebijakan Publik serta

Ilmu-ilmu Sosial Lainnya. Edisi Pertama. Cetakan Pertama. Jakarta. Prenada Media

David, Fred R. 2009. Manajemen Strategis: Konsep-konsep. Edisi ke 12.Jakarta : Salemba Empat

Hapsari, Pradnya Paramita. 2011. Pelaksanaan Penjaminan Kredit Usaha Mikro Kecil dan Menengah (UMKM) Terhadap Pertumbuhan Ekonomi Daerah (Studi di Pemerintahan Kota Batu).Jurnal Wacana Vol 17, No 2. Jurusan Administrasi Publik. Fakultas Ilmu Admistrasi.Universitas Brawijaya

Tjiptono F, Chandra G. 2007. Service, Quality \& Satisfaction. Yogyakarta: CV Andi Offset

Krisnamurthi,B.2001.Agribisnis.Jakarta:Yayasan Pengembangan Sinar Tani 